\title{
Natural trace elemental markers for adult red rock lobsters Jasus edwardsii vary among replicate distinct water masses
}

\author{
Lucy Jack ${ }^{1, *}$, Stephen R. Wing ${ }^{1}$, Yi Hu${ }^{2}$, May Roberts ${ }^{1}$ \\ ${ }^{1}$ Department of Marine Science, 310 Castle Street, University of Otago, Dunedin 9054, New Zealand \\ ${ }^{2}$ Advanced Analytical Centre, James Cook University, Townsville, Queensland 4811, Australia
}

\begin{abstract}
In order to determine the potential utility of trace elemental natural tags to resolve fine-scale stock structure and residency patterns in adult crustaceans, we investigated whether concentrations of trace elements in exoskeleton could be used to resolve capture sites of red rock lobsters Jasus edwardsii. Using inductively coupled plasma mass spectrometry, we measured ratios of Li, Mg, Mn, Ba and Sr to Ca in samples of exoskeleton from 4 pairs of inner fjord and outer coast sites in Fiordland on New Zealand's southwest coast. Water column salinity structure was characterised at these 8 sites from a 12 yr series of conductivity, temperature and depth casts. Information on capture site, sex, carapace length and moult stage was used in an information theoretic framework to assess the degree to which capture site could be statistically discriminated using trace element signatures of exoskeleton. Using a permutational multivariate analysis of variance, we found significant differences in trace elemental signatures of exoskeleton at the scale of 10 to $20 \mathrm{~km}$ for 2 of the 4 fjords. In these same 2 fjords, we found persistent differences in water column salinity structure between sites. A multivariate permutational assignment test (canonical analysis of principal coordinates) successfully reclassified individuals from all 4 pairs of sites better than chance. These results indicate that trace elements can effectively be used to discriminate capture sites of adult rock lobsters between regions with different water mass characteristics. Within these limits, trace elements of exoskeleton may prove effective as natural tags to provide valuable information on fine-scale stock structure and residency patterns for rock lobsters.
\end{abstract}

KEY WORDS: Trace elements $\cdot$ Jasus edwardsii $\cdot$ Metapopulation $\cdot$ Natural tag $\cdot$ Fjord

\section{INTRODUCTION}

Natural tags are a powerful tool to discriminate between discrete subpopulations and determine population connectivity, either by adult movement or larval dispersal (Thorrold et al. 1998, 2001). Chemical tags confer advantages over artificial ones, as all individuals may be marked in a local population. This eliminates problems associated with artificially applied tags such as bias associated with recapture methods, low recapture rates and the associated high cost per unit recovery. However, success in using natural tags lies in (1) choosing a tag that varies sufficiently to provide resolution at the temporal and spatial scales of interest, (2) determining those spatial scales, and then (3) interpreting the pattern of variability to discriminate the population structure. Signatures of trace elements in biogenic structures may reflect environmental conditions at the time of accretion and are increasingly being applied to resolve palaeoclimatic conditions (Dodd \& Crisp 1982), anthropogenic disturbance (Gillikin et al. 2005), and dispersal patterns leading to population connectivity of marine fauna (Thorrold et al. 2007). Perhaps the 
most well defined application is the use of otoliths in the study of teleost fish (Elsdon et al. 2008), but other biogenic structures that have provided valuable information include scales, eye lenses and fin rays or spines of fishes (Gillanders 2001), shells of mytilid mussels (Becker et al. 2005), statoliths of neogastropod larvae (Zacherl et al. 2003) and whole larvae of decapod crustaceans (Anastasia et al. 1998, DiBacco \& Levin 2000, DiBacco \& Chadwick 2001, Carson et al. 2008). In these cases, natural tags are used to infer relatively short time scale dispersal patterns relevant to population dynamics.

Influences on variability of trace elemental tags in biogenic carbonates are described by a growing body of experimental and field-based research (Thorrold et al. 2007, Elsdon et al. 2008, Beer et al. 2011). Some elements are consistent indicators of spatial variability in environmental parameters, such as water chemistry, salinity and temperature, as they are incorporated into calcified structures via substitution for calcium (e.g. $\mathrm{SrCO}_{3}$ in otoliths; Campana 1999, Elsdon \& Gillanders 2003). Others are less useful as natural tags, because they are more controlled by physiological processes and active incorporation, or may leach from structures once accreted (in otoliths: N, K, Cl, Zn, Cu; Proctor \& Thresher 1998, Rooker et al. 2001, Miller et al. 2006).

When identifying connectivity among subpopulations using natural tags, an important assumption is that changes in the environment experienced by the individuals sampled are matched by associated changes in the trace elemental chemistry of the calcareous part. The crustacean exoskeleton poses a distinct challenge in this respect because unlike hard parts of other organisms, it is not accreted over the duration of a lifetime but is shed periodically and replaced to enable growth. Over the moult cycle, lobsters and crayfish elaborate 2 types of calcified structure: exoskeleton and gastroliths (Musgrove 2000).

Gastroliths are paired transitory calcium deposits that are formed pre-moult on the gut lining, from calcium that is reabsorbed from the exoskeleton (Travis 1960, Luquet \& Marin 2004). They serve to allow rapid de-mineralisation of the exoskeleton premoult, enabling the animal to escape the exuviate and facilitate rapid re-mineralisation of key body parts including mandibles and walking limbs (Shechter et al. 2008). The amount of calcium excreted or stored varies among species, and the post-moult exoskeleton is further re-mineralised with calcium sourced exogenously including from ingested exuviae and from the surrounding sea water (Travis 1960). Thus moult cycle periodicity, movement patterns associ- ated with moulting behaviour and the moult stage at the point of sampling have unquantified implications for the use of exoskeleton as a material for natural tags. This presents several distinct questions for the use of exoskeleton as a vehicle for natural tags. How do trace element concentrations vary among local sub-populations? How much of the variability in trace elemental signatures can be attributed to size, sex and moult stage versus geographic location?

Testing these ideas for crustacean exoskeleton requires identifying subpopulations living in discrete environments with persistent differences in environmental or water mass characteristics. The complex coastline of Fiordland, New Zealand, offers an ideal system in this regard, with a broad range of physical environmental conditions from the wave-exposed outer coast to the estuarine inner fjord, resulting in strong gradients in salinity between these 2 primary habitats. The resulting physical gradients drive strong gradients in benthic productivity (Cornelisen et al. 2007, Wing et al. 2007), generating a diverse array of habitats. Along these gradients, consistent patterns in larval dispersal and adult movement patterns likely result in a source-sink structure for populations of benthic invertebrates (Wing et al. 2003, Perrin et al. 2004) and fish (Rodgers \& Wing 2008, Lawton et al. 2010), as well as the red rock lobster Jasus edwardsii (Jack et al. 2009, Jack \& Wing 2010). In addition, the strong physical gradients associated with the surface low-salinity layer influence distinct patterns in incorporation of trace elements into biogenic carbonate of mussels Mytilus galloprovincialis (Beer et al. 2011). These characteristics result in an ideal testing ground for the use of natural tags for resolving geographic patterns in populations of $J$. edwardsii.

The red rock lobster Jasus edwardsii is widespread throughout the coastal waters of New Zealand and southeastern Australia. Adults are commonly found on rocky reefs from depths of 5 to $275 \mathrm{~m}$ (Phillips 2006). J. edwardsii possess an annual reproductive cycle with a 6 mo incubation stage (MacDiarmid 1989) and produce phyllosoma larvae with a planktonic duration of 9 to 12 mo (Chiswell et al. 2003). Lack of genetic distinction between Australia and New Zealand suggests gene flow via trans-Tasman larval transport (Ovenden et al. 1992, Chiswell et al. 2003). The moult cycle of J. edwardsii varies among size classes and between sexes in an interplay between the cost and benefit of growth and mating that likely depends on the size structure of conspecifics (MacDiarmid 1989, Phillips 2006). In Fiordland, the main moulting period for females is from January to 
August, with mature females moulting from February to July (Annala \& Bycroft 1988). Most males moult during June to August, although some immature males (carapace length $<100 \mathrm{~mm}$ ) undergo a second moult in summer (December to February; Annala \& Bycroft 1988). In general, fast-growing juvenile or sub-adult individuals may moult twice per year whilst mature animals moult only once (MacDiarmid 1989). Tagging studies of the movement of adults (using plastic tags) indicate counter-current along-shore migrations of a proportion of small male and female lobsters around the New Zealand South Island (Booth 1997). Other size- and sex-specific short-distance movements of this species are associated with moulting and mating (inshore), feeding and larval release (offshore; Street 1969, McKoy \& Leachman 1982, MacDiarmid 1991). These movements have the potential to influence local levels of recruitment to fisheries and the efficacy of spatial management strategies in conserving stocks (Freeman et al. 2009), but are not well resolved in the Fiordland region.

In the present study, we investigated whether ratios of trace elements to $\mathrm{Ca}$ in exoskeleton may be used as natural tags to resolve site fidelity of stocks of rock lobsters in Fiordland, New Zealand. This investigation aims to provide sufficient 'proof-of-concept' to enable consideration of whether using trace element signatures from crustacean exoskeleton as natural tags warrants further development. Firstly, we describe oceanographic conditions in the inner and outer regions of 4 fjords, with particular emphasis on the structure of the low-salinity layer. Secondly, using solution based inductively coupled plasma mass spectrometry (ICP-MS), we measured concentrations of 6 trace elements $(\mathrm{Ba}, \mathrm{Ca}, \mathrm{Li}, \mathrm{Mg}, \mathrm{Mn}$ and $\mathrm{Sr}$ ) that are likely to be incorporated into calcareous structures of marine fauna in proportion to their concentration in seawater (reviewed by Thorrold et al. 2007, Elsdon et al. 2008), in the exoskeleton of rock lobsters caught at these 8 sites. In order to assess spatial variability in our potential natural tags, we aimed to ascertain whether trace elemental signatures varied between lobsters caught in different fjords and between inner and outer regions within fjords. In addition, we aimed to determine whether behavioural patterns (depth distributions, inshore-offshore movements) that likely vary with lobster size, sex and moult stage influence trace elemental signatures. Thus we assessed spatial variability in trace element to Ca ratios in lobster exoskeleton and compared the co-variability of lobster size, sex and moult stage to variability in elemental signatures. We then considered the spatial variability measured in trace element signatures in exoskeleton, relative to local oceanographic conditions.

\section{MATERIALS AND METHODS}

\section{Oceanographic surveys}

Fiordland oceanographic conditions are characterised by a persistent low-salinity layer, so the longterm salinity structure of the water column is a good proxy to describe the physical properties of water masses in this system (Stanton \& Pickard 1981, Stanton 1986). Oceanographic surveys were conducted between 1998 and 2010 at each site using a Seabird SBE-19 conductivity, temperature and depth (CTD) profiler, which sampled at $0.5 \mathrm{~s}$ intervals and was lowered at $0.5 \mathrm{~m} \mathrm{~s}^{-1}$. Surveys were conducted in 10 of 12 years, and not all sites were surveyed in all years (mean: 7.8 surveys site ${ }^{-1}$ ). Data from surveys were post-processed to $0.5 \mathrm{~m}$ bins using standard SeaBird processing algorithms for the pumped SBE-19, and used to describe the long-term average salinity structure of the water column at each site. Salinity is temporally highly variable within the low-salinity layer, in response to freshwater inputs (Stanton \& Pickard 1981, Stanton 1986, Gibbs et al. 2000, Gibbs 2001). Sampling events included periods of both high and low rainfall, and a long-term average was calculated to provide a robust description of the salinity conditions vertically through the water column and between sites.

\section{Field collection of lobsters}

In March 2009, 94 lobsters were collected by hand while SCUBA-diving at 8 sites in Fiordland, New Zealand (Fig. 1). Pairs of sites were selected in 4 fjords where lobster populations were known to occur in the inner and outer regions of each fjord (Wing \& Jack 2010), and the maximum possible numbers of lobsters (range: 4 to 23) were opportunistically collected at each site. Each lobster was non-lethally sampled for 1 pleopod using dissecting scissors, and 1 sub-terminal pereopod (walking limb) using the autotomic limb severance response, whereby the animal releases the limb to escape. All samples were frozen until later analysis. The carapace length of each lobster, from the rostral tip to the posterior margin of the carapace, was measured to the nearest mm using Vernier callipers, and the sex was determined by the presence of ventral glands in males and by the terminal pereopod, which is subchelate in females. 


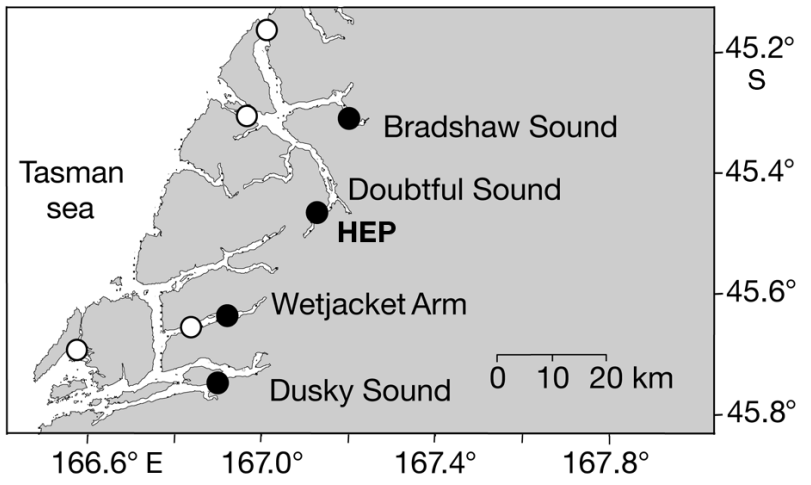

Fig. 1. Fiordland, southwest New Zealand: (O) outer fjord sites; $(\bullet)$ inner fjord sites; HEP: tailrace outflow from the Manapouri hydroelectric power station

\section{Moult stage determination in lobsters}

Because elemental concentration in exoskeleton may vary due to structural changes (e.g. hardening and softening) during the moult cycle, the moult stage of lobsters was determined following Musgrove (2000) using field assessment of cephalothorax rigidity and observations of the distal half of 1 pleopod using a compound microscope. We categorised lobsters only into the 3 broadest classes (post-moult, inter-moult and pre-moult) for simplicity and accuracy, based on pleopod epidermal retraction, setal formation and the degree of cuticle development. Only pre-moult and inter-moult stages were found in our samples, likely due to the timing of sampling.

\section{Trace elemental analysis of lobster exoskeleton}

Lobster exoskeleton comprises 4 layers of cuticle, all of which except the innermost layer are mineralised by the precipitation of calcium carbonate and amorphous calcium phosphate into a chitin-protein cholesteric matrix (Luquet \& Marin 2004). For inclusivity of all potentially usefully components, we analysed the elemental composition of the exoskeleton without separating organic from inorganic material. Exoskeleton was dissected from the leg using $10 \%$ quartz-distilled (QD) $\mathrm{HNO}_{3}$ acid-leached Teflon forceps and mechanically cleaned of adhering tissue by scouring with an acid-washed brush and Milli-Q water. Exoskeletal pieces were acid washed in $0.2 \%$ QD $\mathrm{HNO}_{3}$ for $20 \mathrm{~s}$ in individually washed HDPE vials, triple rinsed in Milli-Q water and air-dried under a class 100 laminar flow fume hood for $3 \mathrm{~d}$. To aid even dissolution, samples were hand-ground to a fine powder using an agate mortar and pestle. As lobster exoskeleton contains about $25 \%$ organic tissue (Y. Hu unpubl. data), approximately $0.25 \mathrm{~g}$ of the ground samples were hot digested in acid-washed perfluoroalkoxy digestion vessels using $3 \mathrm{ml}$ SupraPur $^{\circledR}$ (Merck) double QD $\mathrm{HNO}_{3}, 1 \mathrm{ml}$ analytical reagent grade $\mathrm{H}_{2} \mathrm{O}_{2}$ and $4 \mathrm{ml}$ of Milli-Q water. After approximately $1 \mathrm{~h}$ of unheated digestion, samples were heated in a microwave oven (Milestone Start D) to $180^{\circ} \mathrm{C}$ for $10 \mathrm{~min}$. After cooling, the digested samples were diluted to $300 \mathrm{ml}$ using Milli-Q before analysis using a Varian 820-MS ICP-MS over a 2 d period. Samples were analysed simultaneously for $\mathrm{Ca}$ and 5 other elements ( $\mathrm{Ba}, \mathrm{Sr}, \mathrm{Li}, \mathrm{Mg}$ and $\mathrm{Mn})$. One procedural blank ( $\left.1 \% \mathrm{HNO}_{3}\right)$ was included in each batch of samples $(n=5)$, and a series of multi-element standard solutions containing all the elements of interest were used to calibrate the instrument. The elements $\mathrm{Sc}_{\mathrm{c}} \mathrm{Ga}, \mathrm{Y}$ and In were used as internal standards to correct for drift and matrix effects, and samples from each site were run together in random order to avoid artificial site differences created by machine drift. Certified Reference Material National Institute for Environmental Studies (NIES, Japan) No. 22 Fish Otolith was used as the quality control sample, because initial tests showed that this is the commercial standard most similar to lobster exoskeleton (Y. Hu unpubl. data). Standards were measured after calibration and then after every 30 samples. Detection limits were calculated as 3 times the standard deviation of 10 measures of a $1 \% \mathrm{HNO}_{3}$ blank.

\section{Statistical analysis}

Differences in salinity structure in the upper water column ( 0 to $10 \mathrm{~m}$ depth) between pairs of sites within each fjord were tested using ANOVA. All other statistical analyses were performed using PERMANOVA+ for PRIMER v.6 (Primer-E), which calculates $\mathrm{p}$-values under permutation, thus avoiding assumptions of normality and homogeneity of variance (Anderson 2001). Data were normalised to account for inter-elemental differences in variance. First, a PERMANOVA tested for differences in elemental signatures of lobsters captured among fjords (fixed, 4 levels) and among inner and outer regions nested within fjords (random, 2 levels). A nested design was chosen because inner and outer regions in the different fjords were not considered environmentally equivalent (Wing \& Jack 2010). Opportunistic capture of lobsters led to uneven sampling of different sexes, size classes and animals at different moult stages. Because these factors have potentially 
important implications for elemental signatures in exoskeleton, the PERMANOVA test used sequentially fitted terms to compare their relative importance and to assess the relative importance of the remaining variability due to capture site.

Second, multivariate elemental signatures were compared between exoskeleton samples collected from inner and outer regions in each of the 4 fjords using PERMANOVA. The level of inter-individual variability (dispersion) in multivariate elemental signatures among groups was compared using permutational homogeneity of variance (PERMDISP) tests, which use the ANOVA F-statistic to compare distances of observations from their group centroid. Since $p$-values are obtained under permutation of the least squares residuals, assumptions of normality of distribution and homogeneity of variance are avoided. Canonical analysis of principal coordinates (CAP; Anderson \& Willis 2003) was used to obtain a measure of the distinctiveness of the groups in multivariate space by calculating the leave-one-out reclassification success rate to region (inner and outer) in each fjord. Principal coordinate analysis (PCO) was used to construct an unconstrained ordination of the spatial variability in multivariate signatures in each fjord, where axes display eigenvectors, standardised by the square root of their corresponding eigenvalues (Anderson \& Willis 2003). Permutational ANOVAs were used to quantitatively identify inner versus outer fjord differences in individual elements in each fjord.

\section{RESULTS}

\section{Oceanographic survey}

Analysis of average salinity structure of the water column for pairs of sites (inner versus outer) in each fjord revealed significant differences in stratification in Doubtful Sound and in Dusky Sound, but not within Bradshaw Sound and Wetjacket Arm (Fig. 2). In Doubtful Sound and Dusky Sound, inner sites had thicker and less saline low-salinity layers, indicating a large influence of freshwater inputs. At entrance sites for these 2 fjords, the freshwater layers were significantly less saline (Doubtful Sound; $F_{1,313}=$ 13.18, p =0.0003; Dusky Sound; $F_{1,376}=12.87, \mathrm{p}=$ 0.0004). In Wetjacket Arm and Bradshaw Sound, there were no significant differences in average salinity structure between inner and outer fjord sites (Wetjacket Arm; $F_{1,334}=0.16, \mathrm{p}=0.68$; Bradshaw Sound; $\left.F_{1,166}=1.54, \mathrm{p}=0.22\right)$.
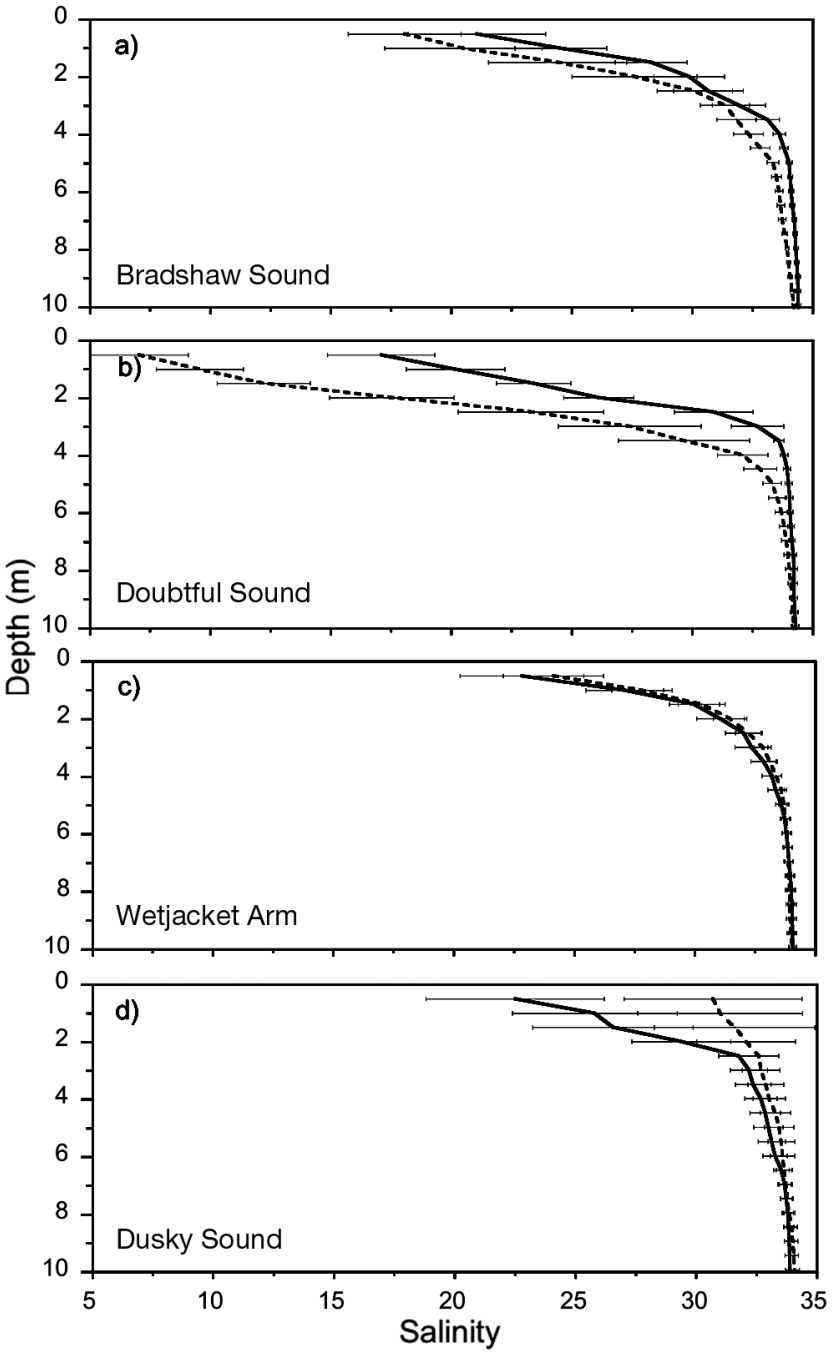

Fig. 2. Average salinity with depth $(\mathrm{m})$ for inner (dashed line) and outer (solid line) sites in (a) Bradshaw Sound, (b) Doubtful Sound, (c) Wetjacket Arm and (d) Dusky Sound. Error bars are $\pm 1 \mathrm{SE}$ among surveys

\section{Elemental analysis}

Multivariate elemental signatures in rock lobster exoskeleton did not vary among the 4 fjords, but did vary among regions of capture (inner or outer) within the fjords (Table 1). When carapace length, moult stage, sex, fjord and region of capture (inner or outer) were modelled sequentially, elemental ratios to $\mathrm{Ca}$ varied significantly with carapace length, but not with moult stage or sex (Table 1). When the variation attributable to carapace length, moult stage, sex and fjord was accounted for, significant variation in elemental signatures was attributable to the region of capture (Table 1).

Multivariate elemental signatures in rock lobster exoskeleton differed significantly between inner and 
Table 1. Jasus edwardsii. Results of PERMANOVA tests of trace elements $\mathrm{Li}, \mathrm{Ba}, \mathrm{Mg}, \mathrm{Mn}$ and $\mathrm{Sr}$ relative to $\mathrm{Ca}$ sequentially fitted to the variables carapace length ( $\mathrm{CL}$, covariate), moult stage (2 levels, fixed), sex (2 levels, fixed), fjord (4 levels, fixed) and region nested within fjord (2 levels, random) including the square root of the estimates of components of variation $(\mathrm{ECV})$, the test statistic pseudo- $F$, the significance value $\mathrm{p}$ calculated under permutation, the number of unique values obtained from 99999 permutations and the degrees of freedom (factor, error). Bold: significant results $(p<0.05)$

\begin{tabular}{|lccccc|}
\hline Factor & ECV & Pseudo-F & $\mathrm{p}$ & $\begin{array}{c}\text { Unique } \\
\text { values }\end{array}$ & $\mathrm{df}$ \\
& & & & & \\
\hline CL & 0.20 & 5.192 & $\mathbf{0 . 0 0 3}$ & 95225 & 1,70 \\
Moult stage & 0.73 & 3.195 & 0.118 & 95636 & 1,70 \\
Sex & 0.36 & 1.823 & 0.08 & 94308 & 1,70 \\
Fjord & 0.07 & 1.115 & 0.317 & 36270 & 3,70 \\
Region (Fjord) & 0.70 & 2.781 & $\mathbf{0 . 0 0 2}$ & 92993 & 4,70 \\
\hline
\end{tabular}

Table 2. Jasus edwardsii. Results of PERMANOVA tests comparing the concentrations of trace elements $\mathrm{Li}, \mathrm{Ba}, \mathrm{Mg}$, $\mathrm{Mn}$ and $\mathrm{Sr}$ relative to $\mathrm{Ca}$ in exoskeleton of lobsters from inner and outer regions of 4 fjords, including the test statistic pseudo- $F$, the significance value $\mathrm{p}$ calculated under permutation, the number of unique values obtained from 9999 permutations and the degrees of freedom (factor, error).

Bold: significant results $(p<0.05)$

\begin{tabular}{|lcccc|}
\hline Fjord & Pseudo- $F$ & $\mathrm{p}$ & Unique values & $\mathrm{df}$ \\
\hline Bradshaw & 1.193 & 0.286 & 9524 & 1,37 \\
Doubtful & 2.740 & $\mathbf{0 . 0 4 8}$ & 4836 & 1,18 \\
Wetjacket & 2.209 & 0.103 & 2993 & 1,12 \\
Dusky & 4.277 & $\mathbf{0 . 0 0 3}$ & 4466 & 1,19 \\
\hline
\end{tabular}

outer regions of Doubtful Sound and of Dusky Sound, but not between inner and outer regions of Bradshaw Sound or Wetjacket Arm (Table 2). No differences in multivariate dispersion (the level of inter-individual variability) in elemental signatures in exoskeleton from inner and outer regions were found for any of the 4 fjords (PERMDISP, $\mathrm{p}>0.05$ ). For each fjord, CAP successfully reclassified samples to inner and outer regions at a greater rate than that predicted by chance alone (Table 3). These classification rates were greatest in Doubtful (90\%) and Dusky (90.5\%) Sounds. The first 2 PCO axes explained $81.3 \%$ (Bradshaw Sound), 80.7\% (Doubtful Sound), 65.4\% (Dusky Sound) and $83.2 \%$ (Wetjacket Arm) of the total variation in elemental signatures (Fig. 3).

Spatial trends in individual elements are shown in Fig. 4. Mg:Ca varied significantly between inner and outer regions of Wetjacket Arm, and Mn:Ca varied significantly between inner and outer regions of
Table 3. Jasus edwardsii. Canonical analysis of principal coordinates (CAP): leave-one-out reclassification to group success rates for inner and outer regions in 4 fjords: Bradshaw, Doubtful, Dusky and Wetjacket. The reclassification success rate predicted by chance alone and sample sizes are given for each experimental group. The significance value $p$, calculated under 9999 permutations, is the exact test result of the null hypothesis that there is no difference in centroids among groups. Bold: significant results $(\mathrm{p}<0.05)$

\begin{tabular}{|llccrc|}
\hline Fjord & Region & $\begin{array}{c}\text { Success } \\
(\%)\end{array}$ & $\begin{array}{c}\text { Chance } \\
(\%)\end{array}$ & $\mathrm{n}$ & $\mathrm{p}$ \\
\hline Bradshaw & Inner & 69.23 & 63.8 & 23 & $\mathbf{0 . 0 3 2}$ \\
& Outer & 53.84 & 36.1 & 13 & \\
Doubtful & Inner & 100 & 20 & 4 & $\mathbf{0 . 0 0 2}$ \\
& Outer & 87.5 & 80 & 16 & \\
Wetjacket & Inner & 75 & 57.1 & 8 & $\mathbf{0 . 0 4 5}$ \\
& Outer & 83.3 & 42.9 & 6 & \\
& Inner & 83.3 & 28.6 & 6 & $<\mathbf{0 . 0 0 1}$ \\
& Outer & 93.3 & 71.4 & 15 & \\
\hline
\end{tabular}

Doubtful and Dusky Sounds. No further significant differences were found for individual elemental ratios between inner and outer regions of each fjord, although a number of marginally non-significant differences were measured (Table 4). Ba:Ca was generally higher in lobsters caught in outer fjord regions except in Dusky Sound. Li:Ca was generally higher in inner fjord regions except Bradshaw Sound. Sr:Ca was generally higher in inner fjord regions except Wetjacket Arm. No consistent patterns between inner and outer regions were found for $\mathrm{Mn}: \mathrm{Ca}$ or $\mathrm{Mg}: \mathrm{Ca}$.

\section{DISCUSSION}

The data and results presented here demonstrate that trace element concentrations in Jasus edwardsii exoskeleton can effectively be used to discriminate the region of capture of individuals collected from regions with different water mass characteristics. Within these limits, trace elements of exoskeleton could potentially be used to provide valuable information on fine-scale connectivity between subpopulations and residency patterns for rock lobsters. Evidence for this comes from 3 patterns observed in our analysis: permutational leave-one-out reclassification success rates for inner and outer fjord regions in 4 fjords each showed significant classification success relative to chance. In these cases, high classification success rates (range from 83 to $100 \%$ ) were replicated in multiple fjord basins in the system, indicating the likely utility of trace elements from 

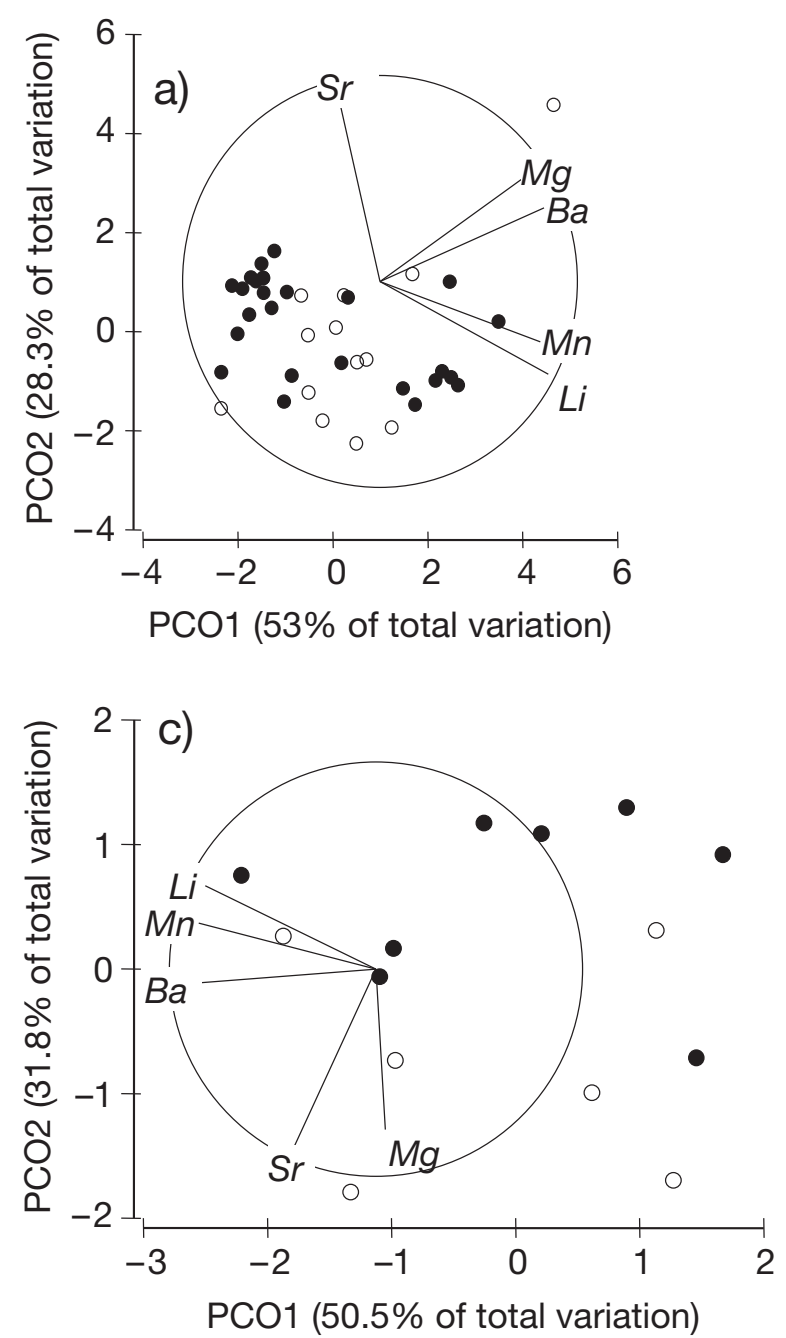
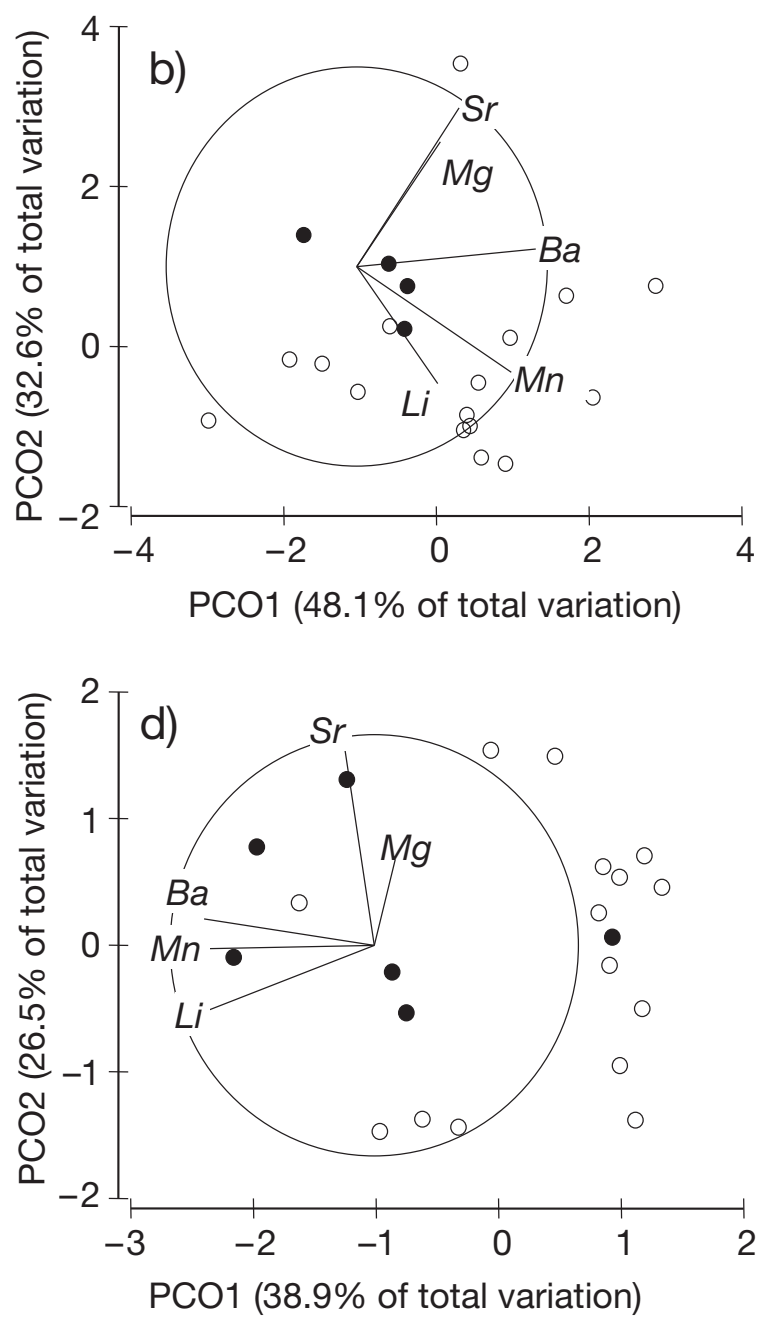

Fig. 3. Jasus edwardsii. Principal coordinate analysis (PCO) of the Euclidean distance between normalised multivariate trace element signatures in lobster exoskeletons from (a) Bradshaw Sound, (b) Doubtful Sound, (c) Wetjacket Arm and (d) Dusky Sound. (O): outer fjord sites; $(\bullet)$ : inner fjord sites

exoskeleton as natural tags in this environment. Secondly, a sequentially fitted permutational MANOVA to test the effect of moult stage, sex, carapace length and region (inner versus outer fjord site) identified only region and carapace length as significant variables in defining exoskeleton elemental signatures. These results indicate that size of individuals and capture site explained more of the variability in trace elemental signatures than did moult stage or sex. We also observed significant differences in multivariate elemental signatures for the pairs of populations (inner versus outer) sampled in Doubtful Sound and Dusky Sound.

The latter pattern in trace elemental signatures of exoskeleton is coincident with differences we observed in the average water column salinity structure among pairs of sites. In Doubtful and Dusky Sounds, there were persistent differences in long-term salinity structure between inner and outer fjord sites as well as significant differences in trace element signatures in lobster exoskeleton between sites. This pattern highlights an important caveat for use of natural tags for studies in population biology. Utility of information from natural tags relies on repeatability in assignment testing for individuals driven by persistent spatial variability in the physical environment. In studies using both fish otoliths and invertebrate larvae, it has been demonstrated that trace element signatures may vary both in space and time. In some cases, this temporal variability creates great difficulty in resolving reliable geographic information, for example from different zones in a fish otolith. In this case, estuarine environments with persistent spatial gradients in water mass type have yielded the most consistent results. 

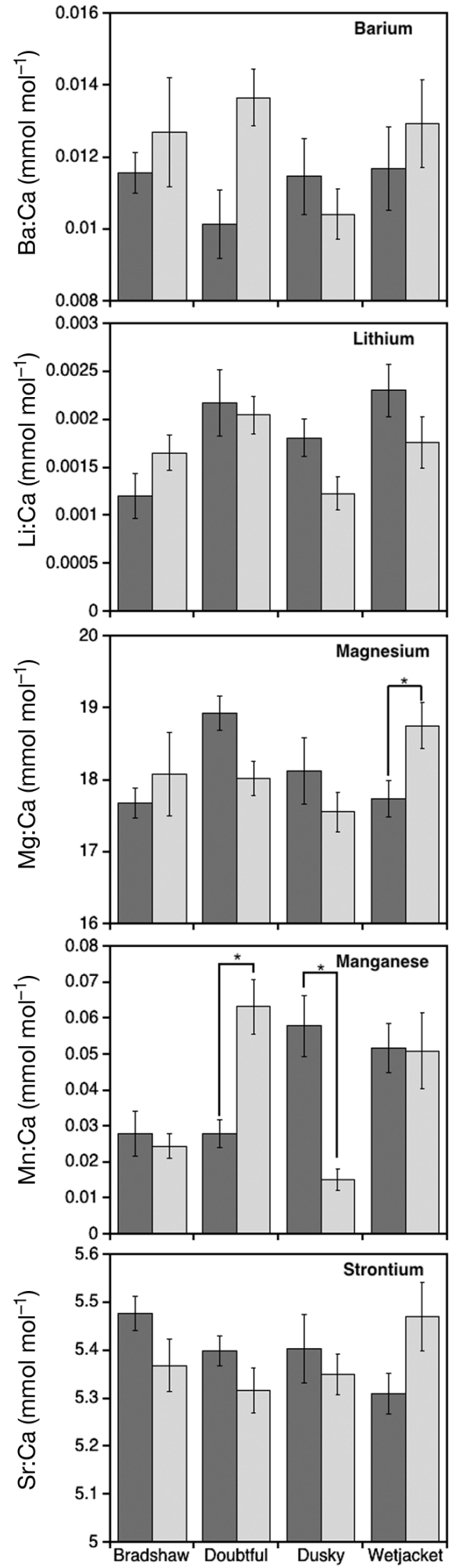

Fig. 4. Jasus edwardsii. Mean $( \pm \mathrm{SE})$ concentrations of $\mathrm{Ba}, \mathrm{Li}$, $\mathrm{Mg}, \mathrm{Mn}$ and $\mathrm{Sr}$ relative to $\mathrm{Ca}$ in lobster exoskeleton from inner (dark bars) and outer regions (light bars) of 4 fjords (Bradshaw Sound, Doubtful Sound, Dusky Sound and Wetjacket Arm). Pairs of sites within fjords connected by a star are significantly different (PERMANOVA, $\mathrm{p}<0.05$ )
Table 4. Jasus edwardsii. Results of PERMANOVA tests comparing the concentration of individual elements relative to $\mathrm{Ca}$ in exoskeleton of lobsters from inner and outer regions of 4 fjords, including the test statistic pseudo- $F$, the significance value $\mathrm{p}$ calculated under permutation, the number of unique values obtained from 99999 permutations and the degrees of freedom (factor, error). Bold: significant results $(\mathrm{p}<0.05)$

\begin{tabular}{|lcrrrr|}
\hline Fjord & Element & Pseudo- $F$ & $\mathrm{p}$ & $\begin{array}{c}\text { Unique } \\
\text { values }\end{array}$ & $\mathrm{df}$ \\
\hline Bradshaw & $\mathrm{Ba}$ & 0.726 & 0.417 & 91997 & 1,37 \\
& $\mathrm{Li}$ & 1.543 & 0.221 & 90607 & 1,37 \\
& $\mathrm{Mg}$ & 0.653 & 0.437 & 91115 & 1,37 \\
& $\mathrm{Mn}$ & 0.140 & 0.714 & 90672 & 1,37 \\
& $\mathrm{Sr}$ & 2.932 & 0.095 & 90385 & 1,37 \\
Doubtful & $\mathrm{Ba}$ & 4.441 & 0.051 & 47841 & 1,18 \\
& $\mathrm{Li}$ & 0.085 & 0.700 & 48822 & 1,18 \\
& $\mathrm{Mg}$ & 3.192 & 0.090 & 48031 & 1,18 \\
& $\mathrm{Mn}$ & 5.085 & $\mathbf{0 . 0 3 7}$ & 47677 & 1,18 \\
& $\mathrm{Sr}$ & 0.708 & 0.419 & 46143 & 1,18 \\
Wetjacket & $\mathrm{Ba}$ & 0.533 & 0.462 & 29881 & 1,13 \\
& $\mathrm{Li}$ & 1.905 & 0.192 & 29657 & 1,13 \\
& $\mathrm{Mg}$ & 6.581 & $\mathbf{0 . 0 2 8}$ & 29645 & 1,13 \\
& $\mathrm{Mn}$ & 0.003 & 0.957 & 29959 & 1,13 \\
& $\mathrm{Sr}$ & 4.109 & 0.065 & 29955 & 1,13 \\
& $\mathrm{Ba}$ & 0.668 & 0.429 & 43006 & 1,19 \\
& $\mathrm{Li}$ & 3.854 & 0.065 & 43269 & 1,19 \\
& $\mathrm{Mg}$ & 1.165 & 0.297 & 43454 & 1,19 \\
& $\mathrm{Mn}$ & 36.858 & $<\mathbf{0 . 0 0 1}$ & 43185 & 1,19 \\
& $\mathrm{Sr}$ & 0.442 & 0.509 & 43120 & 1,19 \\
\hline
\end{tabular}

Crustacean exoskeleton material represents some unique challenges in terms of its utility as a vehicle for natural tags. In the case of Jasus edwardsii, moulting occurs once or twice a year, usually confined to distinct time periods, so animals resident in an area may be 'tagged' at moulting. A corollary is that migrants moving into an environmentally distinct region after moulting may then be discriminated from the local population, if they carry a distinct trace element signature. Environmental tagging of resident lobsters appears to be the case in Doubtful and Dusky Sounds, where both reclassification success rates are high and multivariate trace elemental signatures are distinct between inner fjord and outer coastal sites. These patterns are consistent with the idea that sub-populations in the inner versus outer regions of Doubtful and Dusky Sounds are distinct and may be resident for significant periods of time at a spatial scale of tens of kilometres. Long-term ( $>10$ yr) residency patterns have been observed for red rock lobsters on rocky reefs in other systems (MacDiarmid 1991). In these well-differentiated environments, one could measure trace element signatures of populations over time and estimate migration rates from the outer coastal areas into the inner fjord, or vice versa. Because small 
amounts of exoskeleton material can be sampled non-lethally and trace element signatures are not subject to the vagaries of physical tag retention, natural tags offer a promising method for resolving finescale stock structure in this case.

In Bradshaw Sound and Wetjacket Arm, we did not resolve significant differences in trace elemental signatures of exoskeleton collected among pairs of sites. The observed pattern may be wrought by homogeneity in environmental conditions. Within these 2 fjords, we observed relatively homogeneous salinity structure between inner and outer fjord sites. Alternatively, there may have been greater movement of individuals among these populations, resulting in a greater mixture of trace elemental signatures. While reclassification success for these pairs of sites is significantly better than chance, use of natural tags in these environments may prove less profitable.

Many coastal marine populations are made up of networks of discrete subpopulations linked primarily by larval dispersal and adult migration at the mesoscale (10 to $100 \mathrm{~km}$; Fogarty \& Botsford 2007). Understanding population dynamics in these species requires the ability to distinguish between discrete subpopulations and to identify dispersal patterns indicative of source-sink or metapopulation structure (Kritzer \& Sale 2006). This is especially important when deciding the appropriate spatial scale for management (Polacheck 1990, Dayton et al. 2000). In the present example, Jasus edwardsii stocks are managed at the regional level (hundreds of kilometres), but a new network of marine reserves provides fine-scale spatial management within individual fjords (tens of kilometres; Wing \& Jack 2010). Our results indicate that natural tags might be effectively used to discriminate among sub-populations of rock lobsters at the scale of individual reserves, and may offer an important tool for resolving metapopulation dynamics at this scale.

The present results indicate the potential for trace elemental analysis of exoskeleton as a method for resolving stock structure of crustaceans and also provide a rich opportunity for future research, as several important questions and caveats remain. (1) The halflife of the trace elemental tag in exoskeleton needs to be experimentally resolved. Because exoskeleton is rapidly remineralised after moulting, we suggest that trace elemental ratios in exoskeleton are likely formed directly post-moult. Post-moult trace elemental signatures will likely deviate from ambient conditions depending on the extent of remineralisation supported by gastrolith chemistry. Because some calcium is reabsorbed from the gastrolith and the ingested exuviate, the 'half-life' of an elemental signature may exceed 1 moult cycle. Experimental quantification of this will allow a time scale to be attached to trace elemental tags. (2) It is not known how much of the variability in trace element signatures of exoskeleton can be attributed to differences in diet versus differences in environmental conditions. (3) As different body parts may be accreted at different rates (Travis 1960), we should test for finescale spatial variation in signatures within single exoskeletons. (4) We do not have a measure of the stability of trace element signatures in exoskeleton. Since crustacean exoskeleton is a complex matrix, there may be some continuous change in trace element composition if animals are exposed to differing environmental conditions.

Our study demonstrates for the first time that trace elemental signatures in exoskeleton of adult crustaceans can be used as natural tags to discriminate between subpopulations at the mesoscale. We have demonstrated that in our system, (1) environmental parameters vary sufficiently at the spatial scale of interest to potentially drive spatial variation in elemental signatures; (2) spatial differences are measurable in the trace elemental signatures in rock lobster exoskeleton, obtained using solution-based ICP-MS; and (3) the trace elemental signatures of rock lobsters in Doubtful and Dusky Sounds indicate distinct population structure at the scale of $10 \mathrm{~km}$.

While the utility of these natural tags for resolving fine-scale movement and residency patterns remains to be fully tested, the ability to discriminate capture sites for subpopulations of rock lobsters offers significant potential as a means to track fine-scale movement patterns in estuarine environments. In Fiordland, as with other complex topographical coastlines and estuaries, evidence for source-sink dynamics in a range of coastal species indicates the importance of migration among habitats for population persistence (Wing 2011). Trace elemental tags provide a marker with the appropriate temporal and spatial resolution to resolve these patterns within the metapopulation (Thorrold et al. 1998). If successfully applied to crustacean populations, this approach may resolve fine-scale population structure undetected by either genetic or direct tagging methods, and provide valuable information for understanding population dynamics and efficacy of spatial management.

Acknowledgements. We thank N. Beer, J. Davis, B. Dickson, P. Hessletine and P. Meredith. Monetary support was provided by the University of Otago Ecology Research Group, the Royal Society of New Zealand Marsden Fund (UO-00213 to S.R.W.) and by the Commonwealth Scholarship \& Fellowship Plan (L.J.). 


\section{LITERATURE CITED}

Anastasia J, Morgan S, Fisher N (1998) Tagging crustacean larvae: assimilation and retention of trace elements Limnol Oceanogr 43:362-368

> Anderson MJ (2001) Permutation tests for univariate or multivariate analysis of variance and regression. Can $\mathrm{J}$ Fish Aquat Sci 58:626-639

> Anderson MJ, Willis TJ (2003) Canonical analysis of principal coordinates: a useful method of constrained ordination for ecology. Ecology 84:511-525

$>$ Annala JH, Bycroft BL (1988) Growth of rock lobsters (Jasus edwardsii) in Fiordland, New Zealand. N Z J Mar Freshw Res 22:29-41

Becker BJ, Fodrie FJ, McMillan PA, Levin LA (2005) Spatial and temporal variation in trace elemental fingerprints of mytilid mussel shells: a precursor to invertebrate larval tracking. Limnol Oceanogr 50:48-61

Beer NA, Wing SR, Hu Y (2011) Physical versus biological control of element incorporation into biogenic carbonate: an in situ experiment in a New Zealand fjord. Mar Ecol Prog Ser 433:289-301

Booth JD (1997) Long distance movements in Jasus species and their role in larval recruitment. Bull Mar Sci 61: 111-128

> Campana SE (1999) Chemistry and composition of fish otoliths: pathways, mechanisms and applications. Mar Ecol Prog Ser 188:263-297

Carson H, Morgan S, Green P (2008) Fine-scale chemical fingerprinting of an open coast crustacean for the assessment of population connectivity. Mar Biol 153:327-335

Chiswell SM, Wilkin J, Booth J, Stanton B (2003) TransTasman Sea larval transport: Is Australia a source for New Zealand rock lobsters? Mar Ecol Prog Ser 247:173-182

$>$ Cornelisen CD, Wing SR, Clark KL, Bowman MH (2007) Patterns in $\delta^{13} \mathrm{C}$ and $\delta^{15} \mathrm{~N}$ signatures of Ulva pertusa: interaction between physical gradients and nutrient source pools. Limnol Oceanogr 52:820-832

Dayton PK, Sala E, Tegner MJ, Thrush S (2000) Marine reserves: parks, baselines and fishery enhancement. Bull Mar Sci 66:617-634

$>$ DiBacco C, Chadwick DB (2001) Assessing the dispersal of brachyuran larvae between regions of San Diego Bay California and nearshore coastal habitats using elemental fingerprinting. J Mar Res 59:53-78

$>$ DiBacco C, Levin L (2000) Development and application of elemental fingerprinting to track the dispersal of marine invertebrate larvae. Limnol Oceanogr 45:871-880

Dodd JR, Crisp EL (1982) Non-linear variation with salinity of $\mathrm{Sr} / \mathrm{Ca}$ and $\mathrm{Mg} / \mathrm{Ca}$ ratios in water and aragonite bivalve shells and implications for palaeosalinity studies. Palaeoclimatol Palaeoecol 38:45-56

> Elsdon TS, Gillanders MM (2003) Reconstructing migratory patterns of fish based on environmental influences on otolith chemistry. Rev Fish Biol Fish 13:217-235

> Elsdon TS, Wells BK, Campana SE, Gilanders BM and others (2008) Otolith chemistry to describe movements and lifehistory parameters of fishes: hypotheses, assumptions limitations and inferences. Oceanogr Mar Biol Annu Rev 46:297-330

> Fogarty MJ, Botsford LW (2007) Population connectivity and spatial management of marine fisheries. Oceanography (Wash DC) 20:112-123

Freeman DJ, MacDiarmid AB, Taylor RB (2009) Habitat patches that cross marine reserve boundaries: conse- quences for the lobster Jasus edwardsii. Mar Ecol Prog Ser 388:159-167

Gibbs MT (2001) Aspects of the structure and variability of the low-salinity-layer in Doubtful Sound, a New Zealand fiord. N Z J Mar Freshw Res 35:59-72

Gibbs M, Bowman M, Deitrich D (2000) Maintenance of near-surface stratification in Doubtful Sound, a New Zealand fiord. Estuar Coast Shelf Sci 51:683-704

Gillanders BM (2001) Trace metals in four structures of fish and their use for estimates of stock structure. Fish Bull 99:401-419

Gillikin DP, Dehairs F, Baeyens W, Navez J, Lorrain A, Andre L (2005) Inter- and intra-annual variations of $\mathrm{Pb} / \mathrm{Ca}$ ratios in clam shells (Mercenaria mercenaria): a record of anthropogenic lead pollution? Mar Pollut Bull 50:1530-1540

Jack L, Wing S (2010) Maintenance of old-growth size structure and fecundity of the red rock lobster (Jasus edwardsii) among marine protected areas in Fiordland, New Zealand. Mar Ecol Prog Ser 404:161-172

Jack L, Wing S, McLeod R (2009) Evidence of prey base shifts in rock lobsters (Jasus edwardsii) in response to habitat conversion: implications for efficacy of newly established marine reserves in Fiordland. Mar Ecol Prog Ser 381:213-222

Kritzer JP, Sale PF (eds) (2006) Marine metapopulations. Elsevier Academic Press, Oxford

Lawton R, Wing S, Lewis A (2010) Evidence for discrete subpopulations of sea perch (Helicolenus percoides) across four fiords in Fiordland, New Zealand. N Z J Mar Freshw Res 44:309-322

Luquet G, Marin F (2004) Biomineralisations in crustaceans: storage strategies. C R Palevol 3:515-534

MacDiarmid AB (1989) Moulting and reproduction of the spiny rock lobster Jasus edwardsii (Decapoda: Palinuridae) in northern New Zealand. Mar Biol 103:303-310

MacDiarmid A (1991) Seasonal changes in depth distribution, sex ratio and size frequency of Jasus edwardsii on a coastal reef in northern New Zealand. Mar Ecol Prog Ser 70:129-141

McKoy JL, Leachman A (1982) Aggregations of ovigerous female rock lobsters, Jasus edwardsii (Decapoda, Palinuridae). N Z J Mar Freshw Res 16:141-146

Miller MB, Clough AM, Bateson JN, Wachet RW (2006) Transition metal binding to cod otolith proteins. J Exp Mar Biol Ecol 329:135-143

Musgrove RJ (2000) Molt staging in the southern rock lobster Jasus edwardsii. J Crustac Biol 20:44-53

Ovenden JR, Brasher DJ, White RWG (1992) Mitochondrial DNA analyses of the red rock lobster Jasus edwardsii supports an apparent absence of population subdivision throughout Australasia. Mar Biol 112:319-326

Perrin C, Wing SR, Roy M (2004) Population genetic structure amongst populations of the sea star Cocinasterias muricata in the New Zealand fjords. Mol Ecol 13: 2183-2195

Phillips B (ed) (2006) Lobsters: biology, management, aquaculture, and fisheries. Blackwell Publishing, Oxford

Polacheck T (1990) Year-round closed areas as a management tool. Nat Resour Model 4:327-354

Proctor CH, Thresher RE (1998) Effects of specimen handling and otolith preparation on concentration of elements in fish otoliths. Mar Biol 131:681-694

Rodgers KL, Wing SR (2008) Spatial structure and movement of blue cod Parapercis colias in Doubtful Sound, 
New Zealand, inferred from $\delta^{13} \mathrm{C}$ and $\delta^{15} \mathrm{~N}$. Mar Ecol Prog Ser 359:239-248

Rooker RJ, Secor DH, Zdanowiczt VS, Itoh T (2001) Discrimination of northern bluefin tuna from nursery areas in the Pacific Ocean using otolith chemistry. Mar Ecol Prog Ser 218:275-282

Shechter A, Berman A, Singer A, Freiman A and others (2008) Reciprocal changes in calcification of the gastrolith and cuticle during the molt cycle of the red claw crayfish Cherax quadricarinatus. Biol Bull (Woods Hole) 214:122-134

Stanton B (1986) Winter oceanographic observations in some New Zealand fiords. N Z J Mar Freshw Res 20: 299-314

Stanton B, Pickard G (1981) Physical oceanography of New Zealand fiords. NZOI Mem 88:3-37

Street RJ (1969) The New Zealand crayfish Jasus edwardsii (Hutton 1875). NZ Dept Fish Tech Rep 30. Ministry of fisheries, Wellington

Thorrold SR, Jones CM, Swart PK, Targett TE (1998) Accurate classifications of juvenile weakfish Cynoscion regalis to estuarine nursery areas based on chemical signatures in otoliths. Mar Ecol Prog Ser 173:253-265

Thorrold S, Latkoczy C, Swart PK, Jones CM (2001) Natal homing in a marine fish metapopulation. Science 291: 297-299

Thorrold S, Zacherl D, Levin L (2007) Population connectivity and larval dispersal using geochemical signatures in calcified structures. Oceanography (Wash DC) 20:80-89

Editorial responsibility: James McClintock, Birmingham, Alabama, USA
Travis DF (1960) The deposition of skeletal structures in the Crustacea. 1. The histology of the gastrolith skeletal tissue complex and the gastrolith in the crayfish, OrConectes (Cambarus) virilis Hagen-Decapoda. Biol Bull (Woods Hole) 118:137-149

Wing SR (2011) Population networks with sources and sinks along productivity gradients in the Fiordland Marine Area, New Zealand: a case study on the sea urchin Evechinus chloroticus. In: Liu J, Hull V, Morzillo A, Weins $\mathrm{J}$ (eds) Sources, sinks and sustainability. Cambridge University Press, Cambridge, p 382-398

Wing SR, Jack L (2010) Biological monitoring of the Fiordland (Te Moana o Atawhenua) Marine Area and Fiordland's marine reserves - 2010. Report prepared for the Department of Conservation. Available at: http://www. fmg.org.nz/documents/fma-ecological-monitoring-2010.pdf

Wing SR, Gibbs MT, Lamare MD (2003) Reproductive sources and sinks within the sea urchin (Evechinus chloroticus) population of a New Zealand fjord. Mar Ecol Prog Ser 248:109-123

Wing S, Leichter J, Perrin C, Rutger S, Bowman M, Cornelisen C (2007) Topographic shading and wave exposure influence morphology and ecophysiology of Ecklonia radiata (C. Agardh 1817) in Fiordland, New Zealand. Limnol Oceanogr 52:1853-1864

Zacherl DC, Manríquez PH, Paradis G, Day RW and others (2003) Trace elemental fingerprinting of gastropod statoliths to study larval dispersal trajectories. Mar Ecol Prog Ser 248:297-303

Submitted: September 29, 2011; Accepted: November 17, 2011 Proofs received from author(s): December 6, 2011 